6.

Derecho canónico 

Revista de Derecho

de la Pontificia Universidad Católica de Valparaíso

XXX (Valparaíso, Chile, $1^{\text {er }}$ Semestre de 2008)

[pp. 295 - 310]

\title{
EL SILENCIO DEL DEFENSOR DEL VÍNCULO EN LA ETAPA DE DISCUSIÓN DE LA CAUSA. CONSECUENCIAS PROCESALES
}

[The Silence of the Defender of the Bond in the Discussion Stage of the

Cause. Procedural Consequences]

\author{
David Albornoz Pavisic* \\ Universidad Pontificia Salesiana (Roma)
}

Resumen

El autor se pregunta por las consecuencias procesales que conlleva el silencio del defensor del vínculo en un momento tan delicado para la labor de un tribunal eclesiástico como es el período de discusión de la causa. El estudio de la respuesta dada por el ordenamiento canónico implica analizar la relación entre la acción del juez y la del defensor del vínculo y, en particular, examinar la normativa que orienta la tarea del defensor del vínculo en la etapa de discusión de la causa, en las diversas hipótesis planteadas en los cánones 1603 y 1606 del Código de Derecho Canónico.

Palabras clave: Derecho canónico - Derecho procesal canónico - Defensor del vínculo - Nulidad matrimonial canónica.

\begin{abstract}
The author wonders about the procedural consequences entailed in the silence of the defender of the bond in such a delicate moment for the task of an ecclesiastic court as the discussion period of the case. The study of the answer the canonic legislation gave implies the analysis of the relationship between the action of the judge and the defender of the bond and, in particular, implies the revision of the norm which guides the defender of the bond's task in the discussion stage of the case, in the different hypotheses posed in canons 1603 and 1606 of the Body of Canonic Law.

Keywords: Canonic law - Canonic procedural law - Defender of the bond - Canonic annulment.
\end{abstract}

* Decano de la Facultad de Derecho Canónico de la Universidad Pontificia Salesiana. Dirección postal: Piazza dell'Ateneo Salesiano 1, 00139 Roma, Italia. Correo electrónico: albornoz@unisal.it 


\section{INTRODUCCIÓN}

Recuerdo que en una ocasión, en un tribunal eclesiástico, se planteó una situación que despertó ciertas perplejidades. En el desarrollo de una causa de nulidad matrimonial en primera instancia, el defensor del vínculo había sido nombrado y le habían sido notificadas las actuaciones del proceso, interviniendo realmente en él. Recibidas las pruebas recogidas en la causa, publicadas las actas y concluido el término para presentar nuevas pruebas, se había decretado la conclusión de la causa. Todo ello fue notificado al defensor del vínculo. El abogado de la parte actora presentó su alegato de bien probado, que fue notificado al defensor del vínculo. En aquel momento, el juez instructor dio a éste un plazo preciso para que emitiera su parecer. Cuatro meses después de cumplida aquella fecha, sin haber recibido la respuesta del defensor del vínculo, se dictó en autos la sentencia definitiva de primera instancia, siendo notificada de acuerdo a derecho.

Nos podemos preguntar ¿qué consecuencias procesales conlleva el silencio del defensor del vínculo, citado regularmente en juicio, en un momento tan delicado para la labor de un tribunal, como es el período de discusión de la causa? ¿Cómo se comprende la relación entre la acción del juez y la del defensor del vínculo, en el contexto del incumplimiento del derecho/deber de este último?

\section{NORMATIVA QUE ORIENTA LA TAREA DEL DEFENSOR DEL VÍNCULO EN LA ETAPA DE DISCUSIÓN DE LA CAUSA}

El decreto de conclusión de la causa cierra la fase instructoria y abre la fase de discusión de la causa. En ésta, las partes argumentan y defienden sus pretensiones en la dinámica del contradictorio procesal, para lo cual deben evaluar los resultados obtenidos a partir del material recogido en el período probatorio. Para ello el tribunal está obligado a establecer en el mismo decreto un plazo conveniente (canon 1601) para que se presenten las defensas y alegatos (de las partes privadas) y las animadversiones $\mathrm{u}$ observaciones (de las partes públicas) ${ }^{1}$. Esta obligación (iudex [...] praestituat) tiene su fundamento en el derecho de defensa de las partes ${ }^{2}$.

1 "Benché il promotore di giustizia e il difensore del vincolo nel Codice di diritto canonico mai vengano col nome di parti, anzi, siano differenziati da loro (cánones 1533, 1561; nel CCEO, cánones 1214 e 1242), la legge li assimila alle parti [...]”. Pinto, José María, La giurisdizione, en Bonnet, Piero Antonio; Gullo, Carlo (editores), Il processo matrimoniale canonico. Nuova edizione riveduta e ampliata (2a edición, Città del Vaticano, Libreria Editrice Vaticana, 1994), p. 129.

2 "Le difese e le osservazioni offrono la sintesi dei fatti e la valutazione e argo- 
Como se puede ver, el proceso judicial como mecanismo para resolver controversias y tutelar derechos en su fase de discusión, involucra no solamente al titular de la potestad, cuyo pronunciamiento concluirá el juicio, sino que comprende a las partes cuya participación se hace particularmente activa en la búsqueda de la verdad mediante la presentación de los argumentos, vinculados obviamente a lo que se ha argumentado en la fase instructoria ${ }^{3}$.

El tejido de derechos y deberes aquí presente puede ser descrito de la siguiente manera:

i) Al juez le corresponde "la dirección de todo el proceso en orden a conocer la verdad objetiva de la situación de los fieles que se presentan ante él" ${ }^{4}$, de modo que orientando su acción pro rei veritate, llegue a definir la causa (dicere ius in casu), dictando sentencia definitiva. En esta tarea al juez le corresponde velar para que cada uno de los que intervienen en el proceso realice su función adecuadamente, de acuerdo a lo que en el derecho se les pide. Este carácter directivo le permite al juez poner en relación, ordenar y armonizar los distintos roles de quienes están llamados a intervenir en el proceso, respetando su autonomía y perfil propios.

ii) En el momento específico de la discusión de la causa, las partes privadas tienen el derecho de exponer sus defensas y alegatos (restrictus iuris et facti) y de presentar réplicas con la modalidad establecida en el canon $1603^{5}$.

iii) El juez tiene el deber de requerir dicha intervención de las partes, fijando un plazo para ello (canon 1601).

iv) Las partes, sin embargo, pueden renunciar a este derecho, en modo expreso, remitiéndose a la ciencia y conciencia del juez o en modo táci-

mentazione delle prove, sempre conforme a verità, ma dal proprio punto di vista. Non si tratta di una lista delle prove raccolte, ma di costruire un ragionamento per sorreggere l'azione o l'eccezione, scalzando anche gli argomenti della controparte". Ramos, Francisco Javier, I tribunali ecclesiastici. Costituzione, organizzazione, norme processuali, cause matrimoniali (Roma, Pontificia Università S. Tommaso D’Aquino, 2000), p. 501.

${ }^{3}$ Cf. Arroba Conde, Manuel, Diritto processuale canonico (2a edición, Roma, Ediurcla, 1994), p. 416.

${ }^{4}$ Grocholewski, Zenon, La función del juez en las causas matrimoniales, en Ius Canonicum 45 (2005), 89, p. 23.

${ }^{5}$ La sensibilidad del ordenamiento canónico por el derecho de defensa de las partes se manifiesta más de una vez en una rica interacción entre el juez y las partes, por ejemplo, el juez puede decretar la prórroga del plazo del período de discusión, antes de su vencimiento, si hay una justa causa para ello, a petición de las partes o después de haber sido oídas, pero su reducción no puede decretarse sin el consentimiento de las partes (canon $1465 \$ 2$ ). 
to, permaneciendo en la inactividad. En estos dos últimos casos, el juez prescinde de sus alegatos y continúa adelante en vista a la decisión de la causa (canon 1606).

v) Cualquiera sea la actitud de las partes privadas, el tribunal está obligado a pedir las animadversiones del defensor del vínculo, cuya figura adquiere una relevancia especial en esta etapa de discusión, teniendo en consideración que, en las causas de nulidad matrimonial, no es necesaria para la parte convenida y ni siquiera para la actora, la intervención del abogado (canon $1481 \$ 3$ ).

vi) El defensor del vínculo, que está llamado a intervenir cuando la ley manda que sean oídas las partes (canon 1434 No 1), tiene el deber institucional de presentar sus observaciones ${ }^{6}$. Es una obligación que encuentra su raíz en el mandato de defender razonablemente el vínculo y como tal no es renunciable, aunque, como se afirma en el canon 1432, pueda cumplirlo señalando al tribunal que no tiene nada que alegar razonablemente a favor del vínculo y que se remite a la justicia del tribunal. ${ }^{7}$

En este tejido de relaciones jurídicas es significativo hacer notar que, con respecto al derecho de argumentar las propias conclusiones en juicio, la ley tiene una actitud distinta tratándose de las partes privadas y públicas. Con respecto a las primeras da un término dentro del cual presentarlas, pero no se espera a que ello se realice efectivamente, ya que pueden renunciar en modo expreso o tácito a este acto procesal. A las segundas, en cambio, se les exigen las observaciones, que siempre deben ser presentadas.

Por lo tanto, el juez puede dictar sentencia aunque las partes privadas no hayan presentado sus defensas, o no lo hayan hecho en tiempo oportuno, o se hayan remitido a la justicia del tribunal. Pero ¿podría decirse lo mismo en el caso en que no se hayan presentado las animadversiones del defensor del vínculo?

${ }^{6}$ Arroba Conde describe al defensor del vínculo como una especie de promotor de justicia para la materia específica del vínculo de la ordenación y del matrimonio, agregando: "È persona pubblica costituita dalla società per attuare la difesa processuale dei vincoli, quando si discute circa la loro validità”. Arroba Conde, Manuel, cit. (n. 3), p. 197.

${ }^{7}$ En una obra reciente Palestro afirma que s i e m p r e el defensor debe presentar sus Animadversiones pro vinculo, ya que -según este autor- es i m p o s i b l e no encontrar en las actas de todo proceso elementos a favor del vínculo. Habría que subrayar que estos e l e m e n t o s deberán siempre estructurarse en una defensa r az o n a b l e del vínculo. Cf. Palestro, Vittorio, Il difensore del vincolo ed il promotore di giustizia (artt. 53-60), en Bonnet, Piero Antonio; Gullo, Carlo (editores), Il giudizio di nullità matrimoniale dopo l'Istruzione "Dignitas connubii". Parte Seconda. La parte statica del processo (Città del Vaticano, Libreria Editrice Vaticana, 2007), p. 189. 
Si bien el ordenamiento no contempla para el defensor del vínculo el derecho de ren unciar a su intervención, de hecho puede ocurrir que éste no cumpla con su misión, en el plazo fijado por el tribunal. Es decir, que no presente observaciones razonables a favor del vínculo o que no comunique al tribunal que no tiene nada que añadir.

\section{EL SILENCIO DEL DEFENSOR DEL VÍNCULO. DIVERSOS ESCENARIOS PROCESALES POSIBLES}

¿Cuál es el valor que el derecho atribuye a este silencio? Se puede traer a colación la clásica regla jurídica Qui tacet, consentire videtur (ubi loqui potuit et debuit), cuya aplicación en ámbito procesal ha recordado el Pontificio Consejo para los Textos Legislativos respondiendo a una consulta sobre el canon 1681. En dicha respuesta, el Consejo ha valorado el silencio como no impugnación, o sea, como consenso tácito, según la regula iuris mencionada, subrayando que el Código atribuye en diversas ocasiones este sentido a la interpretación de la voluntad de quien, legítimamente interpelado, tacet $^{9}$

Pero en la hipótesis de este estudio no nos encontramos frente a las partes privadas, sino frente al silencio de una parte pública en juicio. Nos detendremos en los distintos escenarios procesales en los que este silencio pudiera ocurrir en la discusión de la causa.

${ }^{8}$ Regula iuris XLIII en VI: “Qui tacet consentire videtur", en Corpus Iuris Canonici, Editio lipsiensis secunda post Aemilii Ludouici Richteri curas ad librorum manu scriptorum et editionis romanae fidem recognouit et adnotatione critica instruxit Aemilius Friedberg, Pars secunda, Decretalium collectiones: Decretales Gregorii P. IX, Liber Sextus Decretalium Bonifacio P. VIII, Clementis P. V Constitutiones, Extravagantes tum viginti Ioannis P. XXII, tum communes (Lipsiae, 1881, reimp. Graz, 1959), p. 1123.

${ }^{9}$ Por ejemplo, cuando el actor no obedece a la nueva citación en juicio, se presume su renuncia a la instancia de la litis (canon 1594 n. 2); en el caso de la aplicación del privilegio paulino, el Ordinario del lugar debe interpelar a la parte no bautizada de modo que transcurrido inútilmente el espacio de tiempo concedido para responder, su silencio será considerado como una respuesta negativa (canon $1145 \$ 1$ ); También en el caso del consenso por parte del rector de la iglesia requerido para predicar en ella (canon 764) y en el caso del consenso al menos presunto requerido para impartir la Unción de los enfermos (canon 1003). Cf. Pontificio Consiglio PER I TESTI LEGISLATIVI, Nota explicativa, Responsum ad tres quaestiones propositas circa clausulam "de consensu partium» canon 1681 CIC, en Communicationes 37 (2005) 1, pp. 107-112. 
1. El canon 1603 en relación al art. 243 de la Instrucción Dignitas connubii ${ }^{10}$.

Dentro del plazo asignado por el juez (canon 1601) las partes presentan sus alegaciones y defensas, existiendo el derecho de réplica e, incluso, por una causa grave, con autorización del juez, el derecho a una segunda réplica (canon $1603 \$ 2$ ). En este contexto, el defensor del vínculo tiene siempre el derecho de replicar nuevamente a las respuestas de las partes (canon $1603 \$ 3$ ).

$\mathrm{El}$ art. $243 \$ 1$ de la Instrucción Dignitas connubii se refiere a este derecho del defensor del vínculo de ser oído en último lugar, y, por lo tanto, supone que ya ha habido intercambio de animadversiones ${ }^{11}$. En dicha coyuntura procesal, si el defensor del vínculo no replica, la Instrucción establece una presunción: se considerará que no tiene nada que añadir a sus observaciones ya presentadas ("praesumitur suis animadversionibus nibil addendum habere”) y el juez podrá proseguir con el procedimiento ${ }^{12}$.

El artículo $243 \$ 2$ de la Instrucción Dignitas connubii, al referirse a la réplica del defensor del vínculo, ofrece una primera respuesta a nuestras preguntas dejando asentado, en la hipótesis descrita, el criterio de la primacía de la acción del juez en la conducción de la causa sobre la eventual inacción de las partes, públicas o privadas. Aunque se debe agregar que la intervención del defensor del vínculo, en este caso, de acuerdo al canon $1603 \$ 3$, es facultativa.

\section{El canon 1606 en relación al art. 245 de la Instrucción Dignitas} connubii.

El canon 1606 presenta dos hipótesis desde el punto de vista de las partes: i) "Si las partes descuidan la presentación de la defensa" (renuncia tácita); ii) Si las partes "se remiten a la ciencia y conciencia del juez" (renuncia expresa), frente a las cuales el juez puede "statim" pronunciar sentencia "requisitis animadversionibus [...] defensoris vinculi". El ordenamiento canónico presume la renuncia al derecho de defensa de las partes

${ }^{10}$ Cf. Pontificium Consilium de Legum Textibus, Dignitas connubii. Instructio servanda a tribunalibus dioecesanis et interdioecesanis in pertractandis causis nullitatis matrimonii (Roma, Libreria Editrice Vaticana, 2005).

${ }^{11}$ Incluso el "breve plazo" al que se refiere el art. $243 \$ 2$ corresponde a aquel fijado por el juez para las réplicas en el art. $242 \$ 1$ ("breve tempus a iudice praestitutum ... brevem terminum a iudice statutum").

${ }^{12}$ Viene subrayado por la Instrucción que el derecho de réplica regulado en el canon 1603 es renunciable por todos, también por las partes públicas. Obviamente sería preferible que la renuncia fuese explícita, para evitar incertidumbres, pero puede ser también implícita, al cumplirse el plazo. 
privadas si, en el plazo establecido para ello, no se presentan las respectivas defensas y prevé una iniciativa ex officio del órgano judicial que, como tal, constituye una excepción al principio de impulso procesal a iniciativa de las partes. Dicha excepción está motivada en el respeto al bien público eclesial, amenazado en este caso por la inhibición del deber de las partes ${ }^{13}$.

¿Qué quiere decir que el juez deba "requerir las observaciones" del defensor del vínculo?

En sentido literal, r e qu e r i r no significa o b t e n e r . Este argumento nos podría llevar a sostener que una vez que el juez haya requerido las animadversiones al defensor del vínculo puede decidir la causa, aun cuando aquéllas no hubiesen sido presentadas.

Por otra parte, considerando que el defensor del vínculo es parte pública y que el deber de emitir las animadversiones es preceptivo y no opcional, es decir, que debe manifestar y proponer todo aquello que puede aducir razon ab le m e n te contra la nulidad (canon 1432) o bien "se remittere iudicis scientiae et conscientiae", se puede decir que, en el texto y en el contexto del canon, el significado más adecuado del verbo "requirere" es el de "requerir como necesario", y, por lo tanto, en el sentido de "requerir y obtener"14.

Nos podemos preguntar si r equerir significa, en este caso, la obligación de e s p e r a r a que el defensor del vínculo envíe al juez su parecer ¿Puede actuar el juez sin haber obtenido dichas observaciones? ¿Puede el juez generar otro escenario para salir de este eventual "punto muerto"?

Es relevante constatar que el artículo $245 \$ 1$ de la Instrucción Dignitas connubii, presenta una novedad en relación al descuido en que pueden caer los abogados de las partes, al no presentar sus escritos dentro del plazo útil ${ }^{15}$. Se afirma en la normativa que "debe comunicarse a las partes, advirtiéndoseles que lo hagan dentro del plazo que el juez les otorgue, por sí mismas o por medio de un nuevo abogado legítimamente designado". Se refuerza así el rol activo del juez de cara a las partes y a la actividad que se espera de ellas, por medio de la estipulación de un plazo para el ejercicio de su derecho. Sin embargo, se podría haber planteado que el primer paso a seguir fuese requerir a los abogados que cumplan con su deber dentro de

${ }^{13}$ Cf. De Diego-Lora, Carmelo; Rodríguez-Ocaña, Rafael, Lecciones de derecho procesal canónico. Parte general (Pamplona, Eunsa, 2003), pp. 343-344.

${ }^{14}$ Cf. Chiappetta, Luigi, Il Codice di diritto canonico. Commento giuridico-pastorale (2a edición, Roma, Dehoniane, 1996), III, p. 162.

${ }^{15}$ Una breve referencia a esta normativa en GIL de las Heras, Feliciano, Las pruebas, las causas incidentales, la publicación y la conclusión de la causa en la Instrucción Dignitas connubii, en Ius Canonicum 46 (2006), 91, p. 206. 
un nuevo plazo breve y luego, si ello no fuese eficaz, plantear a las partes que actúen por sí mismas o por medio de un nuevo abogado ${ }^{16}$.

El artículo $245 \$ 2$ parece excluir que el defensor del vínculo entregue sus observaciones en forma oral. Existen diversas opiniones sobre la posibilidad de que el juez pueda aplicar, con el acuerdo de las partes y, por lo tanto, con el consentimiento también del defensor del vínculo, lo dispuesto en el canon $1602 \$ 1$ en una causa matrimonial ${ }^{17}$. Al menos podemos decir que al especificar: "receptis scripto animadversionibus defensoris vinculi, poterit statim sententiam pronuntiare”, la Instrucción está subrayando el deber del defensor del vínculo y precisando el modo de cumplirlo ordinariamente.

La redacción de este parágrafo se debe entender en el marco de la tarea propia de la Instrucción Dignitas connubii, es decir, no como una modificación de la disposición codicial, sino como un esfuerzo de desarrollar o determinar la forma en que ha de ejecutarse el "requirere" establecido en el canon 1606. Efectivamente, en la misma Instrucción se subraya que: "ea mente elaborata est atque publici iuris facta ut ausilio sit iudicibus ceterisque tribunalium Ecclesiae administris, quibus ministerium sacrum cognoscendi causas nullitatis matrimonii commissum est. Ideo leges processuales Codicis Iuris Canonici ad declarandam nullitatem manent in toto suo vigore, ad quas semper referendum erit in istructione interpretanda". Por lo tanto,

${ }^{16}$ Cf. García Faílde, Juan José, La instrucción 'Dignitas connubii' a examen (Salamanca, Publicaciones Universidad Pontificia de Salamanca, 2006), p. 213.

${ }^{17}$ Ramos subraya que lo dispuesto en el canon 1602 difícilmente será aplicable en las causas matrimoniales, generalmente complejas, y más aún teniendo en consideración lo establecido en el canon 1690, cf. Ramos, Francisco Javier, cit. (n. 2), p. 503. Arroba Conde en cambio no excluye la posibilidad de la discusión oral, cf. ArrobA Conde, Manuel, cit. (n. 3), p. 419. García Faílde expresa sus dudas en propósito y se inclina por decir que dicha facultad del juez no se extiende a las causas de nulidad matrimonial, cf. GARCía FAÍlDE, Juan José, Nuevo derecho procesal canónico, Estudio sistemático-analitico comparado ( $3^{\text {a }}$ edición, Salamanca, Publicaciones Universidad Pontificia de Salamanca, 1995), p. 208. Sin embargo, este autor, en otra obra, comentando el art. 240 de Dignitas connubii, plantea la posibilidad que los escritos de defensa y de alegatos puedan ser sustituidos por el juez, con el consentimiento de las partes, por una discusión oral en sede del tribunal, cf. GARCía FAÍldE, Juan José, La Instrucción, cit. (n. 16) p. 210. Por otra parte, Ortiz afirma que el art. $240 \$ 1$ de la Instrucción Dignitas connubii, exige que las partes presenten sus defensas y observaciones por escrito, excluyendo la posible excepción del canon 1602, cf. OrTIZ, Miguel, Il difensore del vincolo, en Franceschi Héctor; Llobell Joaquín; Ortiz, Miguel, La nullità del matrimonio: temi processuali e sostantivi in occasione della "Dignitas connubii" (Roma, Edizioni Università della Santa Croce, 2005), p. 57. 
por su misma naturaleza, la Dignitas connubii siempre viene interpretada subordinadamente a las normas del Código ${ }^{18}$.

\section{Una tercera situación.}

Otro contexto posible consiste en que las partes presenten en tiempo sus defensas y no existan réplicas a éstas. Si en tal situación se produce el silencio del defensor del vínculo, no son aplicables las disposiciones del canon 1606, pues no se cumple ninguna de las dos hipótesis ahí recogidas, ni tampoco es aplicable el art. 243, ya que no hubo réplicas. Las preguntas planteadas más arriba vuelven a repetirse.

\section{ELEMENTOS PARA UNA INTERPRETACIÓN}

Ciertamente la fase de discusión no es superflua en el desarrollo de un proceso, ni tampoco - como subraya Arroba Conde- puede ser considerada una concesión psicológica de utilidad sólo para las partes y sus abogados. Hablamos de un verdadero derecho a argumentar las propias conclusiones, cuya violación puede llevar a la nulidad de la sentencia, en cuanto sea lesionado el derecho de defensa. Estamos frente a un momento clave en el desarrollo del contradictorio ${ }^{19}$.

Si el defensor del vínculo de hecho no cumple con su función, que es un verdadero deber jurídico, debemos preguntarnos por la causa inmediata de este incumplimiento, pues ello permitirá delimitar las consecuencias jurídicas. Hay que distinguir: i) Si el defensor del vínculo no ha sido citado y no se ha presentado para entregar sus animadversiones y tampoco ha podido cumplir su misión antes de la sentencia, mediante el examen de las actas. ii) Si fue citado regularmente, pero no cumple con su deber.

En el primer caso se aplican los cánones 1433 y 1620 n. 7 y la sentencia adolece de nulidad insanable. En el segundo caso pareciera que, ante todo, lo que le corresponde hacer al juez es buscar provocar la respuesta del defensor del vínculo, dirigiéndole, en virtud de su función directiva de todo el proceso, una monición por escrito. En ella podrá establecer un nuevo término de días para que cumpla con su deber ${ }^{20}$, o bien, - si no lo

${ }^{18}$ Cf. Montini, Gian Paolo, L'Istruzione Dignitas connubii nella gerarchia delle fonti, en Periodica 94 (2005) 3, pp. 475-476.

${ }^{19}$ Cf. Arroba Conde, Manuel, cit. (n. 3), pp. 421-422.

${ }^{20}$ Es una posibilidad que los miembros de la Comisión redactora analizaron en la Sessio V (11-16 diciembre 1978) al discutir sobre el contenido del canon 264, actual 1606, pero refiriéndose a las partes privadas: "De sentencia alicuius organi consultationis addi posset iudicem habere facultatem statuendi novum terminum intra quem partes suas defensiones deferant vel scripto dicant se illis renuntiare. Consultores respondet id 
había hecho- le podrá indicar un plazo para que actúe, pero señalándole en cualquiera de los casos que, más allá de dicho término, se presumirá la renuncia a presentar observaciones y el proceso seguirá adelante. Esto le permitirá al juez, una vez cumplido dicho plazo sin que el defensor intervenga, continuar con el proceso.

La justificación de fondo para esta interpretación se encuentra en la naturaleza de la relación entre el juez y las partes públicas y en el rol directivo del primero de cara a todo el proceso ${ }^{21}$. La obligación de desempeñar un oficio público - defensor de vínculo- que la misma ley regula (cánones 1430 y 1432) "no se traduce, en el ámbito del proceso, en una limitación de la actuación del juez; es decir, si las partes públicas no cumplen con las cargas procesales que les corresponden, ello no implica necesariamente que el juez, acabado el plazo en que debió la parte realizar determinada actuación procesal, no pueda pasar al momento procesal que corresponda" 22 . Por lo tanto, el juez, continúa Rodríguez-Ocańa, una vez solicitadas las observaciones al defensor del vínculo, y transcurrido el plazo sin que se haya presentado tal escrito, "podrá pronunciarse inmediatamente sobre el mérito de la causa", teniendo como único requisito el que estime tener pleno conocimiento de ella ${ }^{23}$. En este sentido otro autor subraya que "el juez no puede ni debe detener el procedimiento a la espera de que el defensor del vínculo cumpla con su deber" ${ }^{24}$.

Esta interpretación podría provocar preguntas acerca de la validez de la sentencia dictada o de la defensa del interés público o incluso acerca del rol del defensor del vínculo. Tratemos de responder a estas eventuales dudas.

El canon 1606 no pone condición invalidante alguna al "requirere" y, por lo tanto, de acuerdo a lo prescrito en el canon 10, debe considerarse válida la sentencia emitida por el juez aunque no se hayan obtenido las

vi canonis non prohiberi. Canon ergo manet uti es". Communicationes 11 (1979) 1, p. 138.

${ }^{21}$ García Faílde señala sobre la eventualidad que el defensor del vínculo omita presentar las animadversiones: "el que deban pedírsele no significa que, si el defensor del vínculo no cumple con su deber, el juez no pueda prescindir de ellas". García FAílde, Juan José, Nuevo derecho procesal canónico, cit. (n. 17), p. 208.

${ }^{22}$ Rodríguez-Ocaña, Rafael, Comentario al canon 1606, en Marzoa, Ángel; Miras, Jorge; Rodríguez-Ocaña, Rafael (editores), Comentario exegético al Código de derecho canónico (2a edición, Pamplona, Eunsa, 1997), IV/2, p. 1520.

${ }^{23}$ Cf. Rodríguez-Ocaña, Rafael, Comentario al canon 1606, cit. (n. 22), p. 1520 .

${ }^{24}$ García Faílde, Juan José, La Instrucción, cit. (n. 16), p. 214. 
observaciones del defensor del vínculo, porque ex actis et probatis rem habeat plane perspectam ${ }^{25}$.

Por otra parte, no se dan los requisitos para plantear una nulidad insanable de la sentencia por violación del ejercicio del derecho a defender el vínculo, por parte del defensor del vínculo (cánones 1433 y $1620 \mathrm{~N}^{\circ} 7$ ). Para que ello ocurra no basta el hecho que éste hubiera debido hacerlo, puesto que existían en las actas argumentos para hacerlo, y no lo hizo, sino que es necesario que al defensor del vínculo se le haya negado la posibilidad de ejercer su función, al no haber sido citado, iis non citatis acta irrita sunt. Esta hipótesis no se concreta en la medida en que le ha sido ofrecida dicha posibilidad, señalándole un plazo suficiente para presentar sus animadversiones en el tiempo oportuno ${ }^{26}$.

En este mismo sentido, Gullo subraya que si bien es verdad que el defensor del vínculo está institucionalmente obligado a exponer todo lo que razonablemente puede decirse contra la nulidad, sin embargo, parece arriesgado sostener que la sentencia pueda ser declarada nula sólo porque el defensor del vínculo no haya, al menos, declarado no tener nada que decir a favor del vínculo ${ }^{27}$.

La opinión de estos autores está en sintonía con la orientación de la jurisprudencia rotal, en la cual, por una parte, se ha afirmado que el defensor del vínculo debe tener la posibilidad de una participación activa en el contradictorio ${ }^{28} \mathrm{y}$, por otra parte, también se ha sostenido que el defensor del vínculo no es parte privada ${ }^{29}$ y que tampoco representa a la parte

${ }^{25}$ En este sentido Chiappetta, Luigi, cit. (n. 14), p. 162.

${ }^{26}$ Cf. García Faílde, Juan José, Tratado de derecho procesal canónico (Salamanca, Publicaciones Universidad Pontificia de Salamanca, 2005), p. 316. En el mismo sentido Arroba Conde subraya: “... basta che il giudice abbia permesso al difensore del vincolo di adempiere il suo compito, senza che si possa accusare di nullità la sentenza emessa senza che il difensore del vincolo abbia dato effettivamente il suo parere". Arroba Conde, Manuel, cit (n. 3), p. 418 nota 3.

${ }^{27}$ Cf. Gullo, Carlo, La pubblicazione degli atti e la discussione della causa, en AA.Vv. Il processo matrimoniale canonico (Città del Vaticano, Libreria Editrice Vaticana, 1994), p. 689: "Mi sembrerebbe comunque azzardato sostenere che la sentenza possa esser dichiarata nulla solo perché il difensore del vincolo non abbia almeno dichiarato di non aver nulla da dire in favore del vincolo, anche se il giudice non gli abbia 'richiesto' le animadversiones, purché però gli sia stato almeno notificato il decreto di fissazione della data della decisione della causa".

${ }^{28}$ Cf. Sent. c. Sabattani, 27 novembris 1959, n. 4c, Ibaguen., en Tribunal Apostolicum Sacrae Romanae Rotae, Decisiones seu sententiae selectae inter eas quae anno 1959 prodierunt cura eiusdem apostolici tribunalis editae (Città del Vaticano, Typis Polyglottis Vaticanis, s/d), LI, p. 563.

${ }^{29}$ Cf. Sent. c. Ewers, 13 iunii 1972, n. 6, Tananariven., en Tribunal Apostolicum Sacrae Romanae Rotae, Decisiones seu sententiae selectae inter eas quae anno 
demandada ${ }^{30}$ y que los derechos privados de las partes son defendidos por sus representantes ${ }^{31}$, puesto que el defensor del vínculo y el promotor de justicia tienen como objetivo la tutela del bien público eclesial. Es por ello que eventuales omisiones en el cumplimiento de sus deberes no constituyen causal de nulidad, como lo afirma un decreto coram Bruno del 31 de mayo de 1985. En dicha causa el patrono de la parte demandada afirmaba: "In praesenti causa, Conventa nullum adiutorium in vinculi Defensore habuit, quia ipse concludit pro nullitate matrimonii. Ex modo sese gerendi in iudicio Defensoris vinculi tum in prima instantia tum in secunda instantia, descendit violatio iuris defensionis partis conventae, quae certo nesciebat vinculi Defensorem conclusum esse pro nullitate matrimonii". A lo que en el decreto se respondió: "Assertum e merito quaestionis exsulat, quia Tutor vinculi non est Patronus vel advocatus partis conventae. Eius munus est quidem vinculum tutare sed modo rationi consentaneo [...]. In casu vero non videtur vinculi Defensor pro nullitate matrimonii decertasse [...]. Attamen dato et non concesso quod Tutor vinculi a munere suo defecerit, nullibi in lege affirmatur tali ex omissione nullitatem sententiarum profluere, cum integrum semper manserit parti ius libere agendi et independenter sese defendendi' ${ }^{32}$.

Por otra parte, en un decreto coram Jarawan se afirma en el mismo sentido: "Nullibi, nec in iuris fontibus et speciatim in novo Codice, qui perfcere et complere voluti veterem Codicem, neque in doctrina vel iurisprudentia refertur defectum recti exercitii vinculi Tutoris muneris provocare sententiae nullitatem [...]. Ceterum vinculi Tutoris munus est iura vinculi tueri non iura partis. Quodsi ille deficiat in explendo suo publico munere, modus eius procedendi minime influit in defectum defensionis partis' ${ }^{\text {'33. }}$.

1972 prodierunt cura eiusdem apostolici tribunalis editae (Città del Vaticano, Libreria Editrice Vaticana, 1981), LXIV, p. 268.

${ }^{30}$ Cf. Sent. c. Wynen, 30 ianuarii 1936, n. 12, Culmen., en Tribunal Apostolicum Sacrae Romanae Rotae, Decisiones seu sententiae selectae inter eas quae anno 1936 prodierunt cura eiusdem apostolici tribunalis editae (Città del Vaticano, Typis Polyglottis Vaticanis, 1944), XXVIII, p. 80; Sent. c. FAgIolo, 30 octobris 1968, n. 5, Bisuntina, en Tribunal Apostolicum Sacrae Romanae Rotae, Decisiones seu sententiae selectae inter eas quae anno 1968 prodierunt cura eiusdem apostolici tribunalis editae (Città del Vaticano, Libreria Editrice Vaticana, 1978), LX, p. 714.

${ }^{31}$ Sent. c. Agustoni, 17 martii 1976, n. 6, Romana, en Tribunal Apostolicum Sacrae Romanae Rotae, Decisiones seu sententiae selectae inter eas quae anno 1976 prodierunt cura eiusdem apostolici tribunalis editae (Città del Vaticano, Libreria Editrice Vaticana, 1987), LXVIII, pp. 122-124.

${ }^{32}$ Decr. c. Bruno 31 maii 1985, n. 5, Novae Aureliae, en Rotae Romanae TriBUNAL, Decreta selecta inter ea quae anno 1985 prodierunt cura eiusdem apostolici tribunalis edita (Città del Vaticano, Libreria Editrice Vaticana, 1997), III, p. 148.

${ }^{33}$ Decr. c. Jarawan 25 ianuarii 1989, n. 4, Clavaren., en Rotae Romanae TriBUNAL, Decreta selecta inter ea quae anno 1989 prodierunt cura eiusdem apostolici 
De todo esto se concluye que no existe motivo para que la función del defensor del vínculo, bien o mal ejercitada, pueda ser relevante en vista a una declaración de nulidad por negación del derecho de defensa ${ }^{34}$.

Ahora bien, nos podemos preguntar ¿cómo queda salvaguardado el interés público que aparece eventualmente desprotegido por el incumplimiento de su deber por parte del defensor del vínculo? El horizonte en el que se asegura la defensa del interés público es el horizonte del accionar del juez ${ }^{35}$. Tal bien público permanece protegido por el tribunal, encargado en todo momento del proceso de la aplicación justa del derecho, para lo cual está dotado de importantes facultades para actuar también de oficio ${ }^{36}$ (canon 1452), justamente para la salvaguardia de ese bien público ${ }^{37}$.

Un discurso aparte, aunque no menos importante, dice relación con los caminos a seguir para afrontar la negligencia del defensor del vínculo en el cumplimiento de sus funciones. Podemos recordar diversas intervenciones de carácter administrativo que vendrían a favorecer un diligente desempeño de sus tareas. Por ejemplo: la amonestación verbal, la amonestación por escrito, el nombramiento de otro defensor del vínculo para la causa en cuestión, la remisión de los antecedentes al moderador del tribunal, la sanción pecuniaria e incluso la remoción del defensor, considerando que, de acuerdo a lo señalado por el canon 1436, estaríamos frente a una justa causa al no haber cumplido las leyes que debía observar, teniendo en cuenta, además, su grave responsabilidad en las causas matrimoniales. De todos modos, estas posibles intervenciones y sanciones disciplinares

tribunalis edita (Città del Vaticano, Libreria Editrice Vaticana 2000), VII, p. 11.

${ }^{34}$ Cf. ERLebach, Grzegorz, Le fattispecie di negazione del diritto di difesa causante la nullità della sentenza secondo la giurisprudenza rotale. Criteri generali e parte statica, en Monitor Ecclesiasticus 114 (1989), 4, p. 536. Por otra parte, en un decreto c. DoRAN la negligencia del defensor del vínculo, unida a otros factores, llevó a conceder una nueva proposición de la causa. Cf. Decr. c. Doran, 3 novembris 1988, Ruremunden., en Rotae Romanae Tribunal, Decreta selecta inter ea quae anno 1988 prodierunt cura eiusdem apostolici tribunalis edita (Città del Vaticano, Libreria Editrice Vaticana, 1999), VI, pp. 206-212.

${ }^{35}$ Rodríguez-Ocaña, Rafael, Comentario al canon 1606, (cit. n. 22), p. 1520.

${ }^{36}$ En este sentido se comprende que el conjunto de la normativa procesal, más allá de su carácter instrumental, es una expresión sintética de los valores defendidos por el ordenamiento canónico. Cf. GHerro, Sandro, Diritto alla difesa nei processi matrimoniali canonici, en Aa.Vv. Il diritto alla difesa nell'ordinamento canonico. Atti del XIX Congresso Canonistico, Gallipoli, Settembre 1987 (Città del Vaticano, Libreria Editrice Vaticana, 1988), pp. 1-16.

${ }^{37}$ Cf. De Diego-Lora, Carmelo, Comentario al canon 1434, en MarzoA, Ángel; Miras, Jorge; Rodríguez-Ocaña, Rafael (editores), Comentario exegético al Código de derecho canónico (Pamplona, Eunsa, 1996), IV/1, p. 841. 
no afectan a la sentencia dictada en primera instancia ni guardan relación con la admisión de la causa a trámite en segunda instancia.

[Recibido el 21 de febrero y aceptado el 7 de abril de 2008].

\section{BIBLIOGRAFÍA}

\section{Curia Romana}

1. Sentencias del Tribunal de la Rota Romana

Sent. c. Wynen, 30 ianuarii 1936, Culmen., en Tribunal Apostolicum Sacrae Romanae Rotae, Decisiones seu sententiae selectae inter eas quae anno 1936 prodierunt cura eiusdem apostolici tribunalis editae (Città del Vaticano, Typis Polyglottis Vaticanis, 1944), XXVIII, pp. 71-86.

Sent. c. Sabattani, 27 novembris 1959, Ibaguen., en Tribunal Apostolicum Sacrae Romanae Rotae, Decisiones seu sententiae selectae inter eas quae anno 1959 prodierunt cura eiusdem apostolici tribunalis editae (Città del Vaticano, Typis Polyglottis Vaticanis, s/d), LI, pp. 559-571.

Sent. c. Fagiolo, 30 octobris 1968, Bisuntina, en Tribunal Apostolicum Sacrae Romanae Rotae, Decisiones seu sententiae selectae inter eas quae anno 1968 prodierunt cura eiusdem apostolici tribunalis editae (Città del Vaticano, Libreria Editrice Vaticana, 1978), LX, pp. 710-722.

Sent. c. Ewers, 13 iunii 1972, Tananariven., en Tribunal Apostolicum Sacrae Romanae Rotae, Decisiones seu sententiae selectae inter eas quae anno 1972 prodierunt cura eiusdem apostolici tribunalis editae (Città del Vaticano, Libreria Editrice Vaticana, 1981), LXIV, pp. 265-275.

Sent. c. Agustoni, 17 martii 1976, n. 6, Romana, en Tribunal Apostolicum Sacrae Romanae Rotae, Decisiones seu sententiae selectae inter eas quae anno 1976 prodierunt cura eiusdem apostolici tribunalis editae (Città del Vaticano, Libreria Editrice Vaticana, 1987), LXVIII, pp. 120-145.

\section{Decretos del Tribunal de la Rota Romana}

Decr. c. Bruno 31 maii 1985, Novae Aureliae, en Rotae Romanae Tribunal, Decreta selecta inter ea quae anno 1985 prodierunt cura eiusdem apostolici tribunalis edita (Città del Vaticano, Libreria Editrice Vaticana, 1997), III, pp. 145-149.

Decr. c. Doran, 3 novembris 1988, Ruremunden., en Rotae Romanae Tribunal, Decreta selecta inter ea quae anno 1988 prodierunt cura eiusdem apostolici tribunalis edita (Città del Vaticano, Libreria Editrice Vaticana, 1999), VI, pp. 206-212.

Decr. c. Jarawan 25 ianuarii 1989, Clavaren., en Rotae Romanae Tribunal, Decreta selecta inter ea quae anno 1989 prodierunt cura eiusdem apostolici tribunalis edita (Città del Vaticano, Libreria Editrice Vaticana 2000), VII, p. 11.

3. Pontificio Consejo para los Textos Legislativos

Communicationes 11 (1979) 1, p. 138.

Pontificio Consiglio Per I testi legislativi, Nota explicativa, Responsum ad tres quaestiones propositas circa clausulam "de consensu partium" canon 1681 CIC, en Communicationes 37 (2005) 1, pp. 107-112. 
Pontificium Consilium de Legum Textibus, Dignitas connubii. Instructio servanda a tribunalibus dioecesanis et interdioecesanis in pertractandis causis nullitatis matrimonii (Roma, Libreria Editrice Vaticana, 2005).

\section{Corpus Iuris Canonici}

Corpus Iuris Canonici, Editio lipsiensis secunda post Aemilii Ludouici RICHTERI curas ad librorum manu scriptorum et editionis romanae fidem recognouit et adnotatione critica instruxit Aemilius Friedberg, Pars secunda, Decretalium collectiones: Decretales Gregorii P. IX, Liber Sextus Decretalium Bonifacio P. VIII, Clementis P. V Constitutiones, Extravagantes tum viginti Ioannis P. XXII, tum communes (Lipsiae, 1881, reimp. Graz, 1959).

\section{Libros}

Arroba Conde, Manuel, Diritto processuale canonico (2a edición, Roma, Ediurcla, 1994).

Chiappetta, Luigi, Il Codice di diritto canonico. Commento giuridico-pastorale (2a edición, Roma, Dehoniane, 1996), III.

De Diego-Lora, Carmelo; Rodríguez-Ocaña, Rafael, Lecciones de derecho procesal canónico. Parte general (Pamplona, Eunsa, 2003).

García Faílde, Juan José, Nuevo derecho procesal canónico, Estudio sistemáticoanalítico comparado ( $3^{\text {a }}$ edición, Salamanca, Publicaciones Universidad Pontificia de Salamanca, 1995).

García Faílde, Juan José, Tratado de derecho procesal canónico (Salamanca, Publicaciones Universidad Pontificia de Salamanca, 2005).

García Faílde, Juan José, La instrucción 'Dignitas connubii' a examen (Salamanca, Publicaciones Universidad Pontificia de Salamanca, 2006).

Ramos, Francisco Javier, I tribunali ecclesiastici. Costituzione, organizzazione, norme processuali, cause matrimoniali (Roma, Pontificia Università S. Tommaso D’Aquino, 2000).

\section{Artículos}

De Diego-Lora, Carmelo, Comentario al canon 1434, en Marzoa, Ángel; Miras, Jorge; Rodríguez-Ocaña, Rafael (editores), Comentario exegético al Código de derecho canónico (Pamplona, Eunsa, 1996), IV/1, pp. 837-844.

ERLEBACH, Grzegorz, Le fattispecie di negazione del diritto di difesa causante la nullità della sentenza secondo la giurisprudenza rotale. Criteri generali e parte statica, en Monitor Ecclesiasticus 114 (1989), 4, pp. 495-556.

Gherro, Sandro, Diritto alla difesa nei processi matrimoniali canonici, en Aa.Vv. Il diritto alla difesa nell'ordinamento canonico. Atti del XIX Congresso Canonistico, Gallipoli, Settembre 1987 (Città del Vaticano, Libreria Editrice Vaticana, 1988), pp. 1-16.

Gil de las Heras, Feliciano, Las pruebas, las causas incidentales, la publicación y la conclusión de la causa en la Instrucción Dignitas connubii, en Ius Canonicum 46 (2006), 91, pp. 177-206.

Grocholewski, Zenon, La función del juez en las causas matrimoniales, en Ius Canonicum 45 (2005), 89, pp. 13-33.

Gullo, Carlo, La pubblicazione degli atti e la discussione della causa, en Bonnet, Piero Antonio; Gullo, Carlo (editores), Il processo matrimoniale canonico. Nuova 
edizione riveduta e ampliata (2 $2^{a}$ edición, Città del Vaticano, Libreria Editrice Vaticana, 1994), p. 689.

Montini, Gian Paolo, L'Istruzione Dignitas connubii nella gerarchia delle fonti, en Periodica 94 (2005), 3, pp. 417-476.

Ortiz, Miguel, Il difensore del vincolo, en Franceschi Héctor; Llobell, Joaquín; Ortiz, Miguel, La nullità del matrimonio: temi processuali e sostantivi in occasione della "Dignitas connubii" (Roma, Edizioni Università della Santa Croce, 2005), pp. 27-68.

Palestro, Vittorio, Il difensore del vincolo ed il promotore di giustizia (art. 53-60), en Bonnet, Piero Antonio; Gullo, Carlo (editores), Il giudizio di nullità matrimoniale dopo l'Istruzione "Dignitas connubii". Parte Seconda. La parte statica del processo (Città del Vaticano, Libreria Editrice Vaticana, 2007), pp. 177-190.

Pinto, José María, La giurisdizione, en Bonnet, Piero Antonio; Gullo, Carlo (editores), Il processo matrimoniale canonico. Nuova edizione riveduta e ampliata (2a edición, Città del Vaticano, Libreria Editrice Vaticana, 1994), p. 129.

Rodríguez-Ocaña, Rafael, Comentario al canon 1606, en Marzoa, Ángel; Miras, Jorge; Rodríguez-Ocaña, Rafael (editores), Comentario exegético al Código de derecho canónico (2a edición, Pamplona, Eunsa, 1997), IV/2, pp. 1518-1520. 